\title{
Frame Approach to Teaching Students Political Vocabulary with the Usage of Graphic-Visual Strategies
}

\author{
Galina A. Trapeznikova ${ }^{1}$, Flera Ya. Khabibullina ${ }^{1}$, Iraida G. Ivanova ${ }^{1}$, Lilya R. Gainutdinova ${ }^{1} \&$ Rita A. \\ Egoshina $^{1}$ \\ ${ }^{1}$ Mary State University, Yoshkar-Ola, Russia \\ Correspondence: Galina A. Trapeznikova, Foreign Language Faculty, Mary State University, Yoshkar-Ola, \\ Kremlevskaya Street 44, Yoshkar-Ola, Mary El, 424000, Russia.
}

$\begin{array}{lcc}\text { Received: February 21, } 2015 & \text { Accepted: March 15, } 2015 \quad \text { Online Published: April 29, } 2015 \\ \text { doi:10.5539/res.v7n8p77 } & \text { URL: http://dx.doi.org/10.5539/res.v7n8p77 }\end{array}$

\begin{abstract}
The aim of this article is to present a series of studies dealing with the term "frame" and different approaches to its analysis in teaching students English political vocabulary with the usage of graphic-visual strategies.

In particular, the article touches upon the problem of correlation between the language and the consciousness of a person on the basis of cognitive paradigm through the forms of different structures, models, pictures, diagrams, charts which refer to one notion "frame".

The article also contains the analysis of "frame" which is generalized and universal system of representing various information including political vocabulary of the main topic "Electoral system in different countries".

And at last it opens the importance of using graphic-visual strategies (Venn L. Tate Marcia, 2008) (Venn diagram, Word Map, A way with Words, Fishbone map, Spider Map, from Here to There, Cluster Map and others) in teaching students political vocabulary.
\end{abstract}

Keywords: frame approach, frame script, cognitive, political vocabulary, lexico-semantic field, the concepts: "power", and "politician", graphic-visual strategy

\section{Introduction}

Scientific-technological progress is connected with the growth of information which the students of higher educational establishments must assimilate. It is conditioned by the necessity of searching methods and technologies of intensive education comprising: information technologies, concentrating teaching, the method of supports, the system of structures, the method or projects, modulating systems and others. It demands analytical-synthetic perfection of educational-scientific material with the goal of shortening and compact representation of the information. It may be fulfilled by the usage of the frame approach.

At the end of the twentieth century, the formation and the development of cognitive trend took place in linguistics. As a result of it has become possible to describe the meanings of the words in full.

This trend aims at mastering the language through the forms of different structures and describing their dependence on each other. In connection with it there is the difference between cognitive paradigm and traditional one.

At present many scientific works have been written (Minsky et al.) devoted to the study of the ways of representing knowledge in the form of frames, diagrams, charts, scripts and graphic-visual strategies etc. which assist better representation and organization of the information in the human consciousness. That's why the problem of teaching students political vocabulary with the usage of frame analysis is quite actual.

At first sight it seems obvious that the term "frame" is used in many scientific pedagogical researches of the previous decades but it hasn't got the precise definition. Modern linguistics hasn't got the definite methods of teaching which study this approach. We keep to the definition of the term which is regarded as the structure of the speaker's language consciousness, as a system of choosing language means, grammar rules, lexical units, language categories structured according to the represented context. 


\section{Results and Discussions}

Before we come to clearing up the possibility of using frame approach in the form of graphic-visual structures in teaching students political vocabulary we will try to dwell upon its history.

The method of supportive summary based on visuality of educational material in the form of pictures, diagrams, charts etc. by V. Ph. Shatalov preceded the frame method. It allowed to shorten the information and to use visual channel effectively.

The theory of framing in linguistics is respectively young but it has got its own history.

At first the term "frame" (in English "frame" is "structure", "base") was introduced by M. Minsky in the 70s of the $\mathrm{XX}^{\text {th }}$ century for marking knowledge for perception of space scenes (investigations in Artificial Intelligence and in Psychology: "problem-spaces" of Newell \& Simon (1972) and another in new large structures that theorists like Shank (1974), Abelson (1974), and Norman (1972) assign to linguistic objects). They were moving away from the traditional attempts in trying to represent knowledge as collections of separate, simple fragments.

The essence of the theory is in that when one encounters a new situation (or makes a substantial change in one's view of the present problem) one selects from memory a structure called a frame.

A frame is a data structure for representing a stereotyped situation. Attached to each frame are several kinds of information how to use the frame.

The "top-levels" of a frame are fixed and represent things that are always true about the supposed situation. The "lower-levels" have many terminals_-"slots" that must be filled by specific instances of data. Collections of related frames are linked together into frame-systems. These are used to make certain kinds of calculations economical (Minsky, 1974).

In this regard visual scene analysis describes the events from different viewpoints and the transformations between different frames represent the effects of moving from one place to another. These visual frame structures make it possible to represent knowledge about facts, analogies and other information useful in understanding.

In addition to it, the frame model of representing knowledge is based on the theory of frame (Minsky) in the form of cognitive (psychological) model of person's memory. Its basis lies in the perception of the surrounding world through the comparison of frames in the memory connected with the new information.

Coming from different treatments of "frame" there are some attitudes which are general: 1) "frame" as a structure representing a stereotype situation; 2) "frame" as a cognitive field which is associated with the lexical units.

According to it we can follow the connection of "frame" with verbal language tool and the cognitive field of consciousness where the language structures are represented through scheme-image-representations of a person's experience (Butorin, 2010).

In other words "frame" is the meaning form of stereotype situations, notions, or words, so it can construct the foundation of any cognitive structure expressed by means of the language. It is the necessary condition for verbal materialization of lexical units and unities "non-material—-mental" and "material—verbal notion" (Butorin).

Such forms comprising "frame" are: images, scripts, Gestalt structures, anagrams, the elements of "item-schema code", strategies, plans, "micro-level" notions of the language, language mental representations, scripts etc. the $1^{\text {st }}$ diagram represents all the components of frame kinds. 


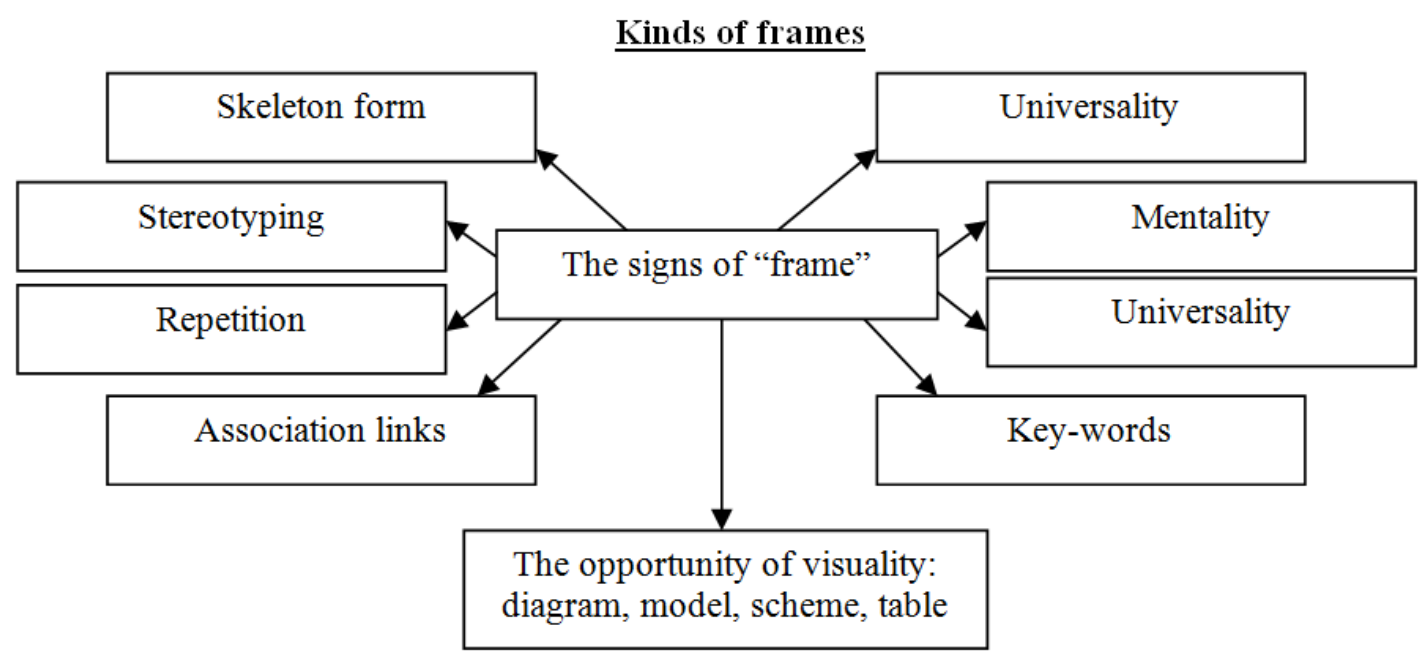

Figure 1. Diagram I (Gurina \& Sokolova, 2005)

It is necessary to comprehend that some scientific works by J. Cerl, D. Wonderveken (the theory of speech acts); A. Vezhbitsky, N. D. Arutyunova (the analysis of dialogue parameters); A. V. Dichkoeva (cognitive pragmatics); L.K. Raxmankulova (cognitive and pragmatic analysis of interrogative sentences) are of great interest for the development of descriptive methods of "frame" in teaching foreign languages. Here is an example of frames in using English vocabulary-grammar (Continuous forms introduced by Dijk, 1985):

1) Social context of frame (informal, private)

"A conversation on the telephone"

- Who were you talking on the phone?

- It was my cousin.

2) Social context (formal, business)

"A conversation with a lawyer"

- How are you going to deal with your client on the account of this case?

- I'll send him a massage.

3) The description of a person's appearance

He looked unusual and untidy; he was wearing a shabby coat and dirty shoes.

4) Social context (informal, social context type)

"Looking for an umbrella"

I don't know where I've left my umbrella.

I was sitting at the desk. I wasn't suggesting it was under the sofa near the desk.

Further "frames" are suggested in the following topics: ("Meeting in the street", "Business conversation", "Reproach", "Conversation between the characters", "Scene in the sitting-room", "Meditations of a hero", "The description of Nature and the actions of a hero", etc.).

It is known that speaking a language is provided by knowing the vocabulary that responds to any changes in society and represents a social form of accumulating social-cognitive experience and passing it to the future generations.

According to the psychological research it must be said that the actualization of a word happens during the first phase of the inner programming at the moment of semantic unfolding as reduced word forms (Vygotsky, Zhinkin, Leontyev, \& Luriya). At the stage of grammar-semantic and motoric realization of a sensible plan the speaker chooses the language devices due to the communicative task.

One of the main areas with the maximum concentration of the ethnic vocabulary, depicting the peculiarities of 
the native speaker's lifestyle, is the socio-political vocabulary (SPV), in which the specifics of the government, the socio-political structure of the society and its history are represented to the fulltest.

The political vocabulary is usually considered in the context of the socio-political vocabulary.

The study of the political vocabulary (PV) is inseparable from the concept of "socio-political vocabulary" (SPV). In the majority of works the analysis of PV takes place in the context of studying SPV.

E.I Sheigal observes that the politics as a specific sphere of human activity is an accumulation of speaking activity owing to its nature (Sheigal). PV has a field structure, in the center of which there are the genres that to its limit comply with the basic assignment of the political communication-race for power. Those are the political debates, the political leaders' speeches, and the election. The author shows that in the peripheral genres the function of racing for power is interwined with the functions of the other types of discourse: judicial, scientific, pedagogical, domestic, medical, religious, etc. The author refers "power" and "a politician" to the basic concepts of the political discourse.

The concept of "power" is expressed with the help of such lexico-semantic groups as" state/country; the government; state symbols; parties/political movements; the election; foreign/domestic policy; the machinery of government; the government branches; services and institutions.

The concept of "a politician" is reflected in such lexico-semantic groups as: head of state; head of government structures (Khabibullina \& Ivanova, 2014).

In this research the frame approach was made possible with the help of lexico-semantic work material in the category of "the election". The basic texts such as the elections in the USA, Canada, France, Russia, and Great Britain are suggested for the study.

Visual-graphic strategies integrate visual and verbal elements of learning. Picture thinking, visual thinking and visual learning are the phenomena of thinking through visual processing. Since $90 \%$ of the brain's sensory input comes from visual sources, it stands to reason that the most powerful influence on learner's behavior is concrete, visual images (Jensen, 1994). Also, linking verbal and visual images increases students' ability to shore and retrieve information (Ogle, 2000).

Graphic strategies are visual representations of linear ideas that benefit both left and right hemispheres of the brain. They assist students in making sense of information, enable them to search for patterns and provide an organized tool for making important conceptual connections.

Visual graphic strategies also known as word webs or semantic mind, and concept maps and they can be used to plan lessons or present information to students.

Using this technique, students should be able to construct their own graphic forms, reflecting their understanding, making up speech patterns on the given topics. So, using visuals as a teaching strategy makes sense.

Each day, students are filled with images from video games, computers and television.

Visual strategies include maps, graphs, charts, and other concrete objects that clarify learning.

These strategies help students make sense of learning by focusing on ways the brain learns best. They help to boost motivation energy and the academic achievements of the students.

The research was held in the Mari State University with full-time students at the faculty of foreign languages (Yoshkar-Ola, Mari El Republic). The political vocabulary is studied by the students in the 8-10 terms (the 4-5 courses). In order to improve the effectiveness of learning there was used frame approach which aims at intensifying the process of political terms learning in lexical semantic fields on the topic "Electoral system in different countries". Graphic visual strategy of learning showed the intensifying effect in education improving the quality and speed of learning and allowed to study and drill this layer of the vocabulary systematically and subsequently. There were also used the materials of different mass media of the English political discourse.

\subsection{Venn Diagram}

A Venn Diagram is a graphic organizer that can help students compare and contrast things.

Using a Venn Diagram makes the information easier to understand and visualize.

The concepts: "compare and contrast" may be used in it.

This information can lead to a deeper understanding of the text in many ways. We instruct the students to work on their own to compare two texts they are reading. They can brainstorm ideas with the partner or work individually. Before the students begin, we must make sure they understand how to record similar and 
constructing ideas in the Venn Diagram.

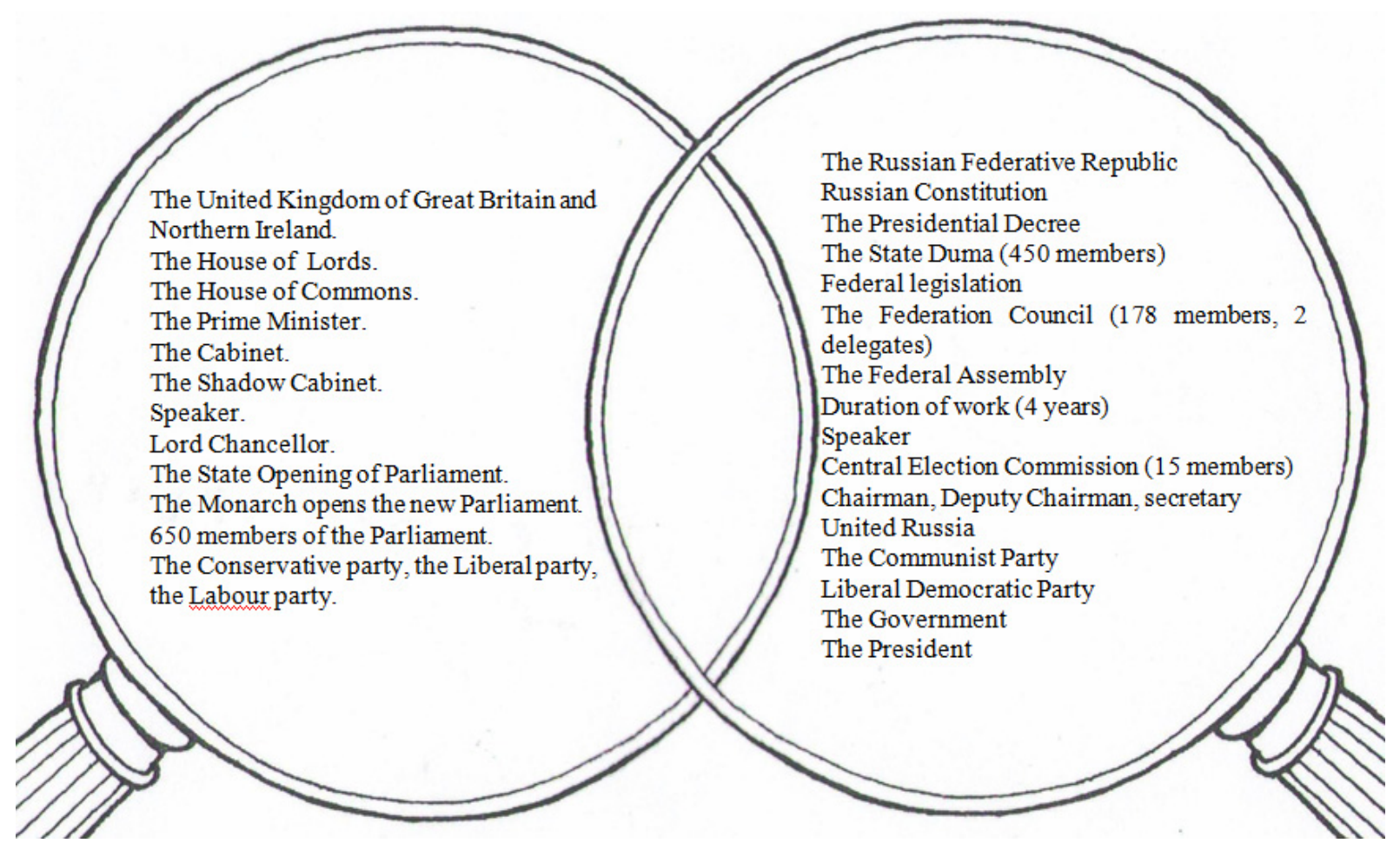

Figure 2. Facts comparison "Elections in Russia and Great Britain"

\subsection{Word Map}

A Word Map is a graphic organizer that helps students build their vocabulary. A word map can be used to list a main topic and related ideas or words ad their synonyms or definitions. The students build a collection of clues that help them retain learning and use the vocabulary words in context. A Word Map graphic organizer can help students decipher difficult words. For this activity we must preselect a vocabulary list and ask students to generate a list of words they don't know, instruct the students to look up the definitions of the words in the dictionary and encourage them to continue filling in the Word Map. 


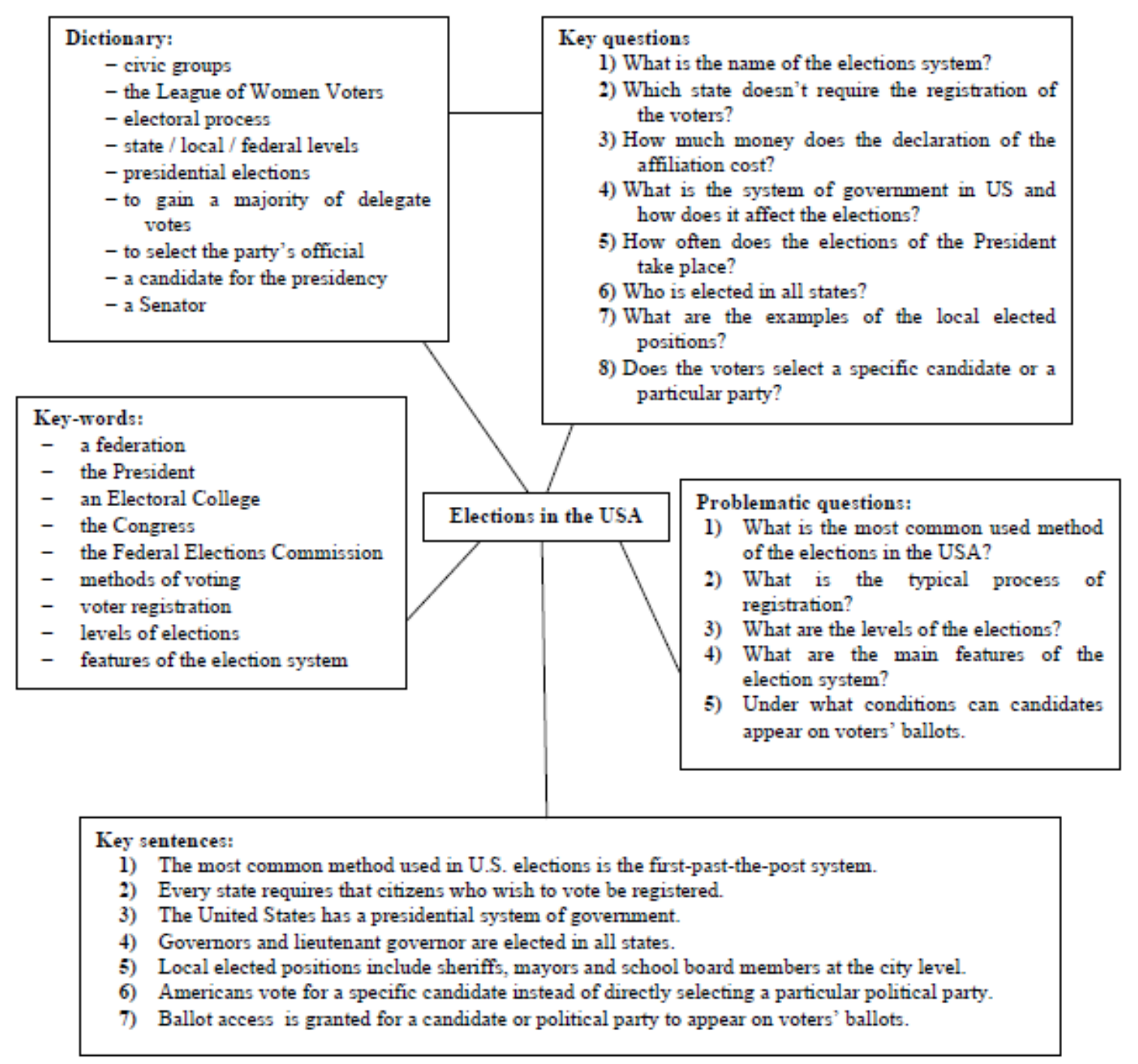

Figure 3. Elections in the USA

\subsection{Fishbone Map}

Students can use a Fishbone Map both during and after reading the text. This kind of graphic organizer allows them to structure ideas on a topic and make multifaceted information more manageable. It provides readers with a framework for recognizing the main idea and supporting details. Ask the students point out the lines on the Map shaped like fishbones. This graphic organizer can help students break down facts in the texts to find main ideas and supporting details. 


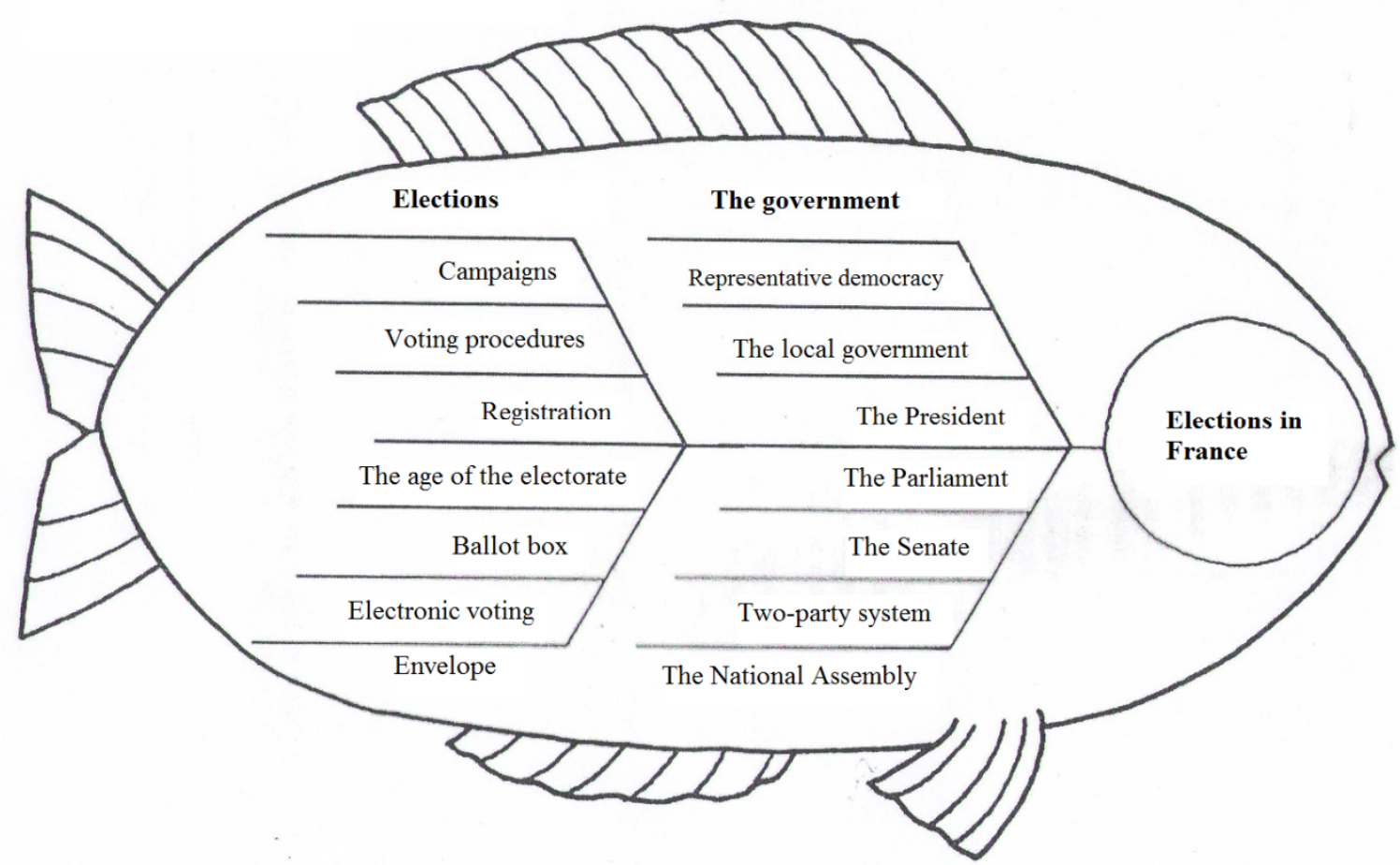

Figure 4. "Elections in France"

\subsection{Spider Map}

A Spider Map allows students to create a visual image of a central idea, process or concept and several subtopics associated with that idea. It is equally useful as a study aid or organizational tool when preparing for a reading or writing assignment. Make sure students understand how to fill out the Spider Map before assigning a passage for independent reading. Encourage students to add more subtopics and details to their map. When all the maps are complete, invite the students to form small groups to discuss how to interpret the reading. 


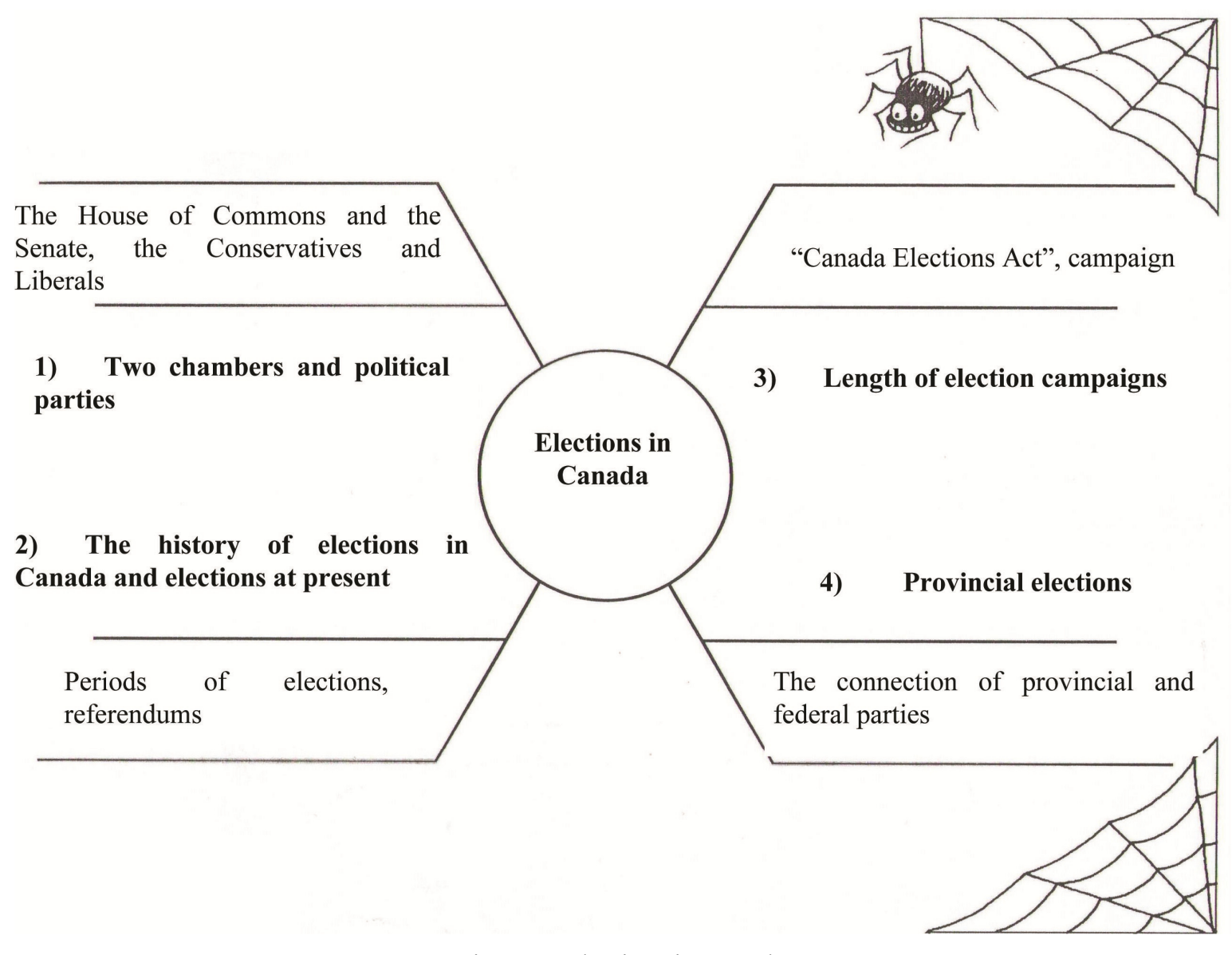

Figure 5. Elections in Canada

\subsection{From Here to There}

This organizer allows the students to visualize the basic rhythm of the facts in the text. It helps students to organize observations and opinions recognize key points and avoid straying from the central focus. By following a simple flowchart students can create a clear easy-to-follow sequence in the political article. Tell the students that each flowchart is on the road that leads from the begging to the end of the article. On this road students can suggest examples and opinions that support or clarify the main points or steps. Such elements will add interest and make the finished work more appealing. 


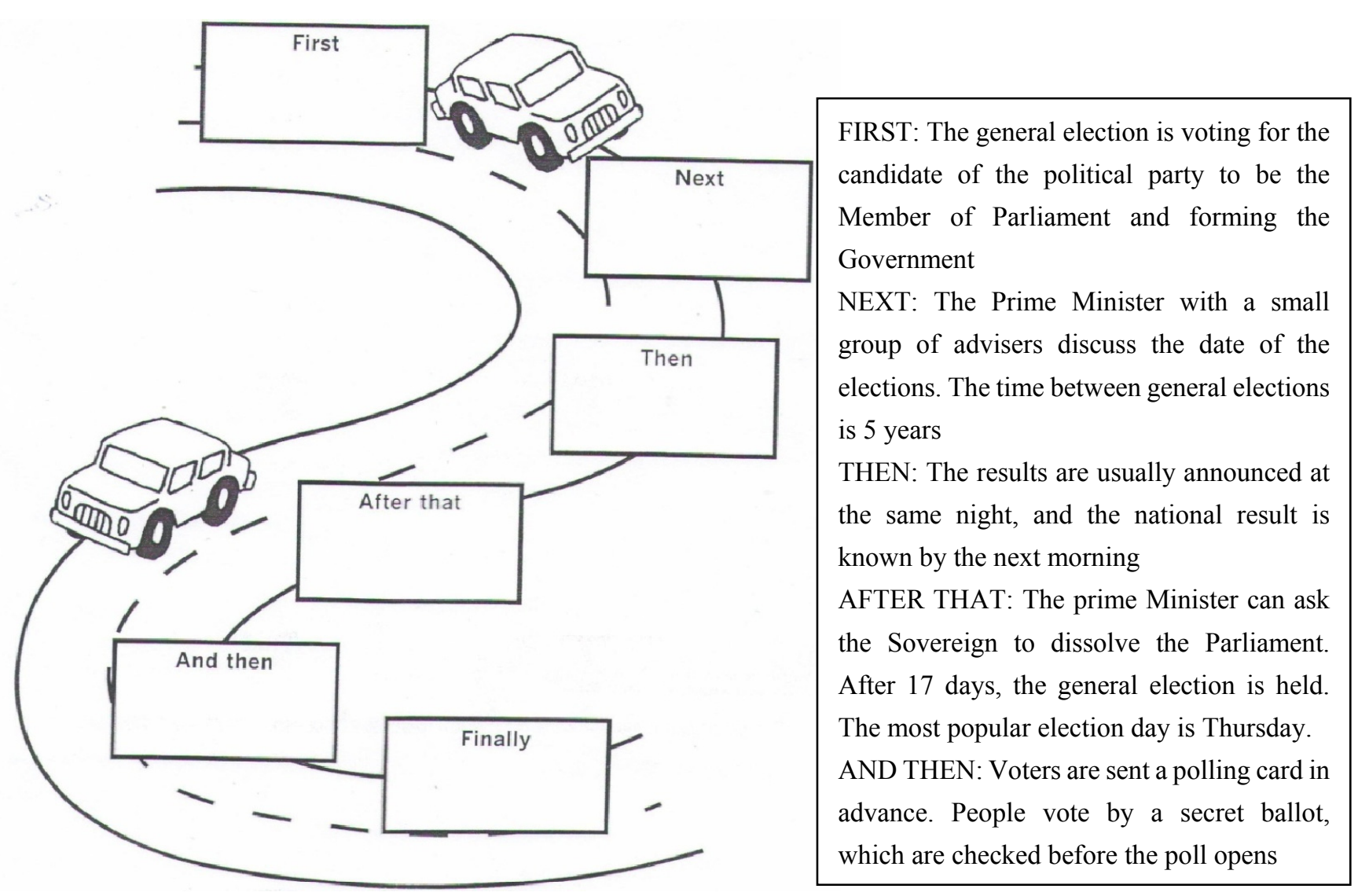

Figure 6. Elections in Great Britain

\subsection{Cluster Map}

Clustering is a non-linear process and naturally encourages lateral thinking. It can stimulate words and images around a key word or topic without interfering with the stream of ideas. Through words and associations, students get a visual map of the creative process that leads to imaginative plot development. This simple tool can help students see connections that might otherwise be missed. Brainstorming is an effective way to build the text. Make students write key-words on the topic. In the next 4 ovals write words or phrases connected to each new extract. They must look for connections that lead to an idea for a text. 


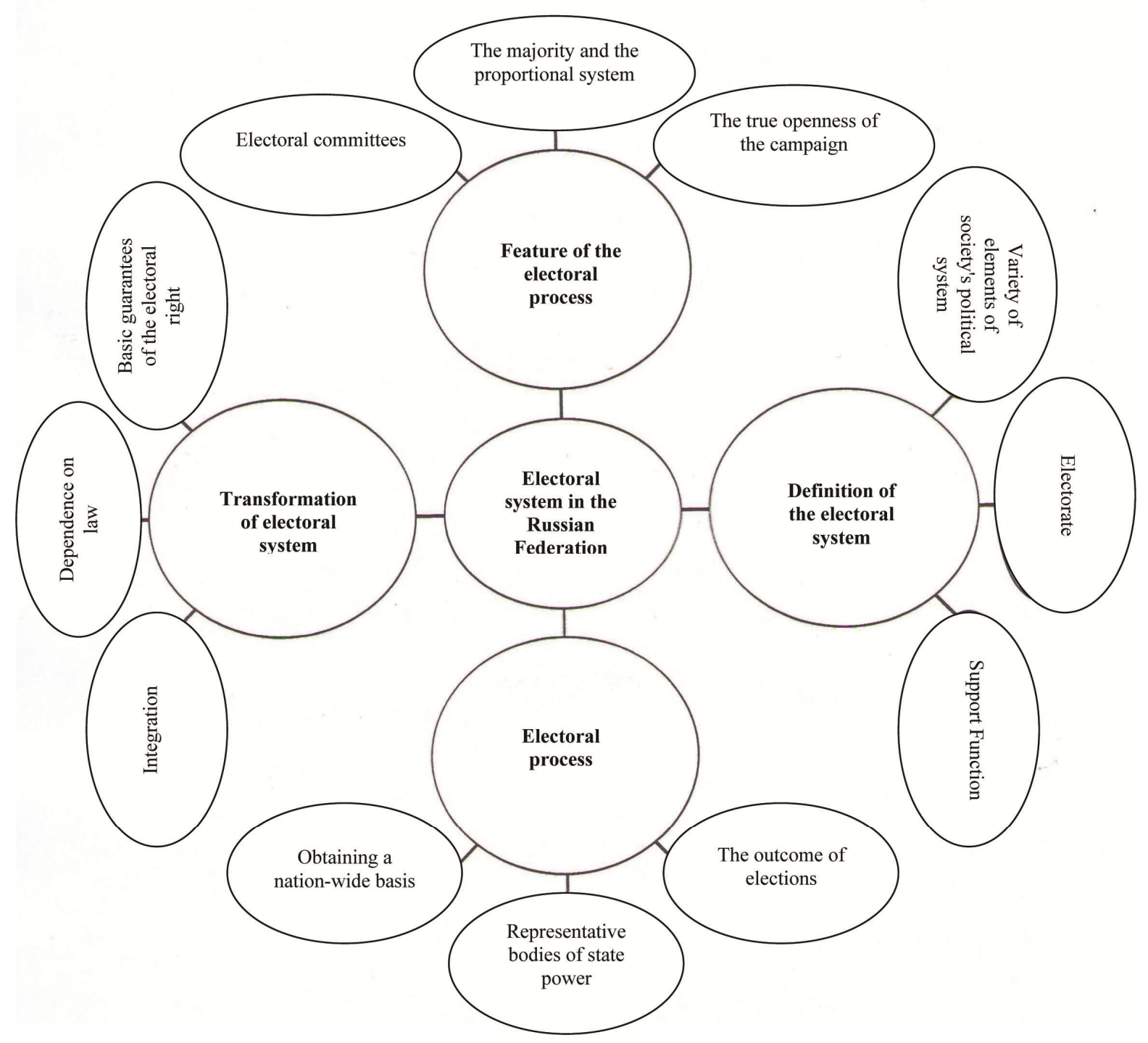

Figure 7. Cluster map

\section{Conclusions}

On the basis of the above we come to the conclusion that frame method is very significant for the investigation of word semantics, because it allows to follow and mark the correlation between linguistic and non-linguistic knowledge, conceptual and lexico-semantic information. The usage of the frame structure makes the task of the language material analysis easier, gives the opportunity to systematize and consider separate units, comprising any "slot" of the model structure more detailed. "Frame" directly takes part in the process of speech communication and attracts their extra-linguistic knowledge of the world.

Frame scheme-algorithms (such as visual organizers) are easily taken in the prolonged memory and intensify the process of students' education and substantially allow to increase the quality and speed of educational potential.

\section{References}

Andor, E. (1985). The Psychological relevance of frames. Quadern; d; semantic, 6(2), 212-221.

Bolgirev, N. N. (2004). The conceptual space of cognitive linguistics. The questions of cognitive linguistics, 1 , 18-36.

Byers, J. (2004). Instructional strategies online: What are graphic organizers. Retrieved from http://otc.spsd.sk.ca/DE/PD/instr/strats/graphicorganizers

Dijk, T. A. (1985). Semantic Discourse Analysis. In T. A. Dijk (Ed.), Handbook of Discourse Analyses (pp. 
150-189). Amsterdam: University Academic Press.

Goffman, E. (1974). Frame analysis. An essay on the organization of experience. N. Y., Northeastern.

Gurina, R. R., \& Sokolova, E. E. (2005). Frame representation of knowledge. Moscow: National Education. NII of schooling Technologies.

Khabibullina, F. Ya., \& Ivanova, I. G. (2014) The Political vocabulary in the Tatar and Mari languages: Simultaneous analysis. The problems of the theory and practice, 1(31), 186-190.

Khabibullina, F. Ya., \& Trapeznikova, G. A. (2014). Graphic-visual strategy of teaching socio-political vocabulary in the Higher Educational Establishment in the conditions of introduction Federal State Educational Standard (FSES). Fundamental investigations, 8, 208-211.

Kopchka, T. J. (2004). Educational Technology Research and Development, 2010. Springer.

Lasarev, V. V., \& Pravikova, L. V. (2002). The theory of a frame: interdisciplined approach. Cognitive paradigm: Frame semantic and nomination. The collection of research articles, 13-19.

Maslennikova, E. (2000). Frame representations of text semantic. Linguistic vestnik, 2, 114-124.

Minsky, M. (1975). A framework for representing knowledge. In P. H. Winston (Ed.), The Psychology of Computer Vision. New York: Mc Graw-Hill.

Nephedova, L. A. (2003). The cognitive approach to interpretation of the text-Collection of research articles (pp. 9-10). Chelyabinsk.

Ogle, D. M. (2000). Make it visual: A picture is worth a thousand words. In M. McLaughlin, \& M. Vogt (Eds.), Creativity and innovation in content area teaching. Norwood, MA: Christopher-Gordon.

Reicher, S. (1996). European Journal of Social Psychology. Wiley Online Library.

Sheigal, E. I. (2000). Symptomatology of the political discourse. Volgograd: Peremena.

Tate, M. L. (2008). Graphic Organizers and other visual strategies. London: Corwin Press Classroom A Sage Publications Company.

\section{Copyrights}

Copyright for this article is retained by the author(s), with first publication rights granted to the journal.

This is an open-access article distributed under the terms and conditions of the Creative Commons Attribution license (http://creativecommons.org/licenses/by/3.0/). 